\title{
Synthesis and performance of a novel polyurethaneurea as pervaporation membrane for the selective removal of phenol from industrial waste water
}

\author{
TARAKRANJAN GUPTA, NARAYAN C PRADHAN ${ }^{\dagger}$ and BASUDAM ADHIKARI* \\ Materials Science Centre, ${ }^{\dagger}$ Department of Chemical Engineering, Indian Institute of Technology, \\ Kharagpur 721 302, India
}

\begin{abstract}
Hydroxyterminated polybutadiene (HTPB) was reacted with 2,4-toluene diisocyanate (TDI) followed by the addition of a diamine chain extender (prepared by the condensation reaction of 4,4'diaminodiphenylsulfone and terepthalaldehyde) to prepare an imine containing polyurethaneurea (PIUU). The prepared polyurethaneurea was caste in order to obtain polymer film. The new polyurethaneurea film showed high phenol selectivity as pervaporation membrane. About $88 \%$ phenol was obtained in condensed permeate when pervaporation was performed at $50^{\circ} \mathrm{C}$ with $7 \%$ aqueous phenol solution as feed and permeate side pressure was maintained at $5 \mathrm{~mm}$ of $\mathrm{Hg}$.
\end{abstract}

Keywords. Pervaporation; HTPB; polyurethane; wastewater; phenol; membrane.

\section{Introduction}

The separation of organic compounds from industrial wastewater is important for the prevention of environmental pollution and recovery of organic compounds for reuse. Many chemical, bio-chemical and physical methods are followed for separation and recovery of organic pollutants. Phenols and other aromatic hydroxy-compounds are common pollutants often found in wastewater streams of petroleum refineries and petrochemical industries (Mancy and Weber 1971). Separation of phenol from industrial waste stream has gathered significant interest over past few decades (Krishnakumar and Sharma 1984). Some important methods regarding recovery of phenols include solvent extraction (Ge and Jin 1996), activated carbon and polymer adsorption (Cook et al 1975; Bercie et al 1996), and membrane processes (Uramoto et al 1991; Ray et al 1997). Membranes with high affinity towards phenol permeability (phenol permselective) such as polyether-block-polyamide (Boddeker et al 1990), modified polydimethylsiloxane (PDMS) (Wu et al 2000) and polyurethane (Hoshi et al 1997) were introduced for improved phenol separation. Modified or unmodified highly hydrophobic hydroxyterminated polybutadiene (HTPB) based polyurethanes were introduced earlier for separation of ethanol-water mixture (Huang et al 1998; Lee et al 1999; Zhao and de Pinho 1999) for selective adsorption of protein (Yang and Lin 2001) and for selective gas transport properties (Chen et al 2000). But no

\footnotetext{
*Author for correspondence
}

report so far has been published on phenol-permselective characteristics of HTPB based polyiminourethaneurea. In this article, we report the synthesis and pervaporation characteristics of a novel HTPB based polyiminourethaneurea (PIUU) film for separation of phenol from phenol water mixture.

\section{Experimental}

\subsection{Materials}

HTPB (functionality $=2 \cdot 4$, hydroxyl value $=43 \cdot 2 \mathrm{mg}$ of $\mathrm{KOH} / \mathrm{g}$ ) with a number average molecular weight of 2580 was received from VSSC (India) and was used as received. 2,4-toluene diisocyanate (TDI) (Fluka AG) was used with further purification. 4,4'-diaminodiphenylsulfone (DADPS) was first dehydrated under vacuum overnight and then was sublimed. Terephthalaldehyde (Fluka AG) was recrystallized from ethanol before use. The catalyst dibutyltindilaurate (DBTDL) (Merck, India) was used as received. Tetrahydrofuran (THF) and methanol were purified before use as per standard procedure.

\subsection{Synthesis of diamine chain-extender}

4,4'-Diaminodiphenylsulfone (DADPS) and terephthalaldehyde were reacted in a round bottom flask at a $2: 1$ mole ratio, refluxing in methanol at $60^{\circ} \mathrm{C}$ for $4 \mathrm{~h}$. The refluxed mixture was cooled and diiminodiamine (A) (scheme 1) crystals were collected by filtration followed by recrystallization from ethanol. 

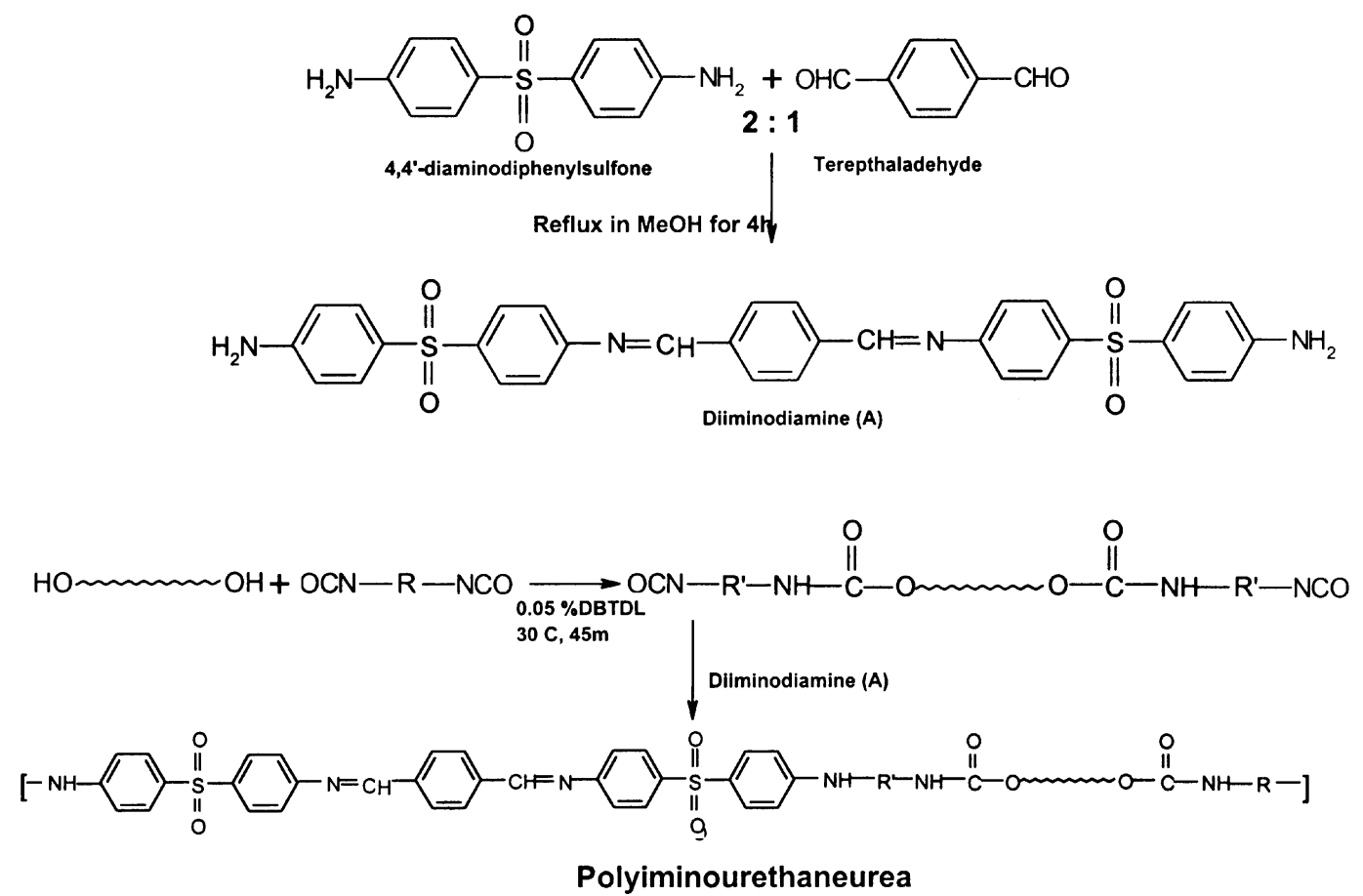

Scheme 1. Synthesis of diiminodiamine and polyiminourethaneurea (PIUU).

\subsection{Synthesis of polyiminourethaneurea membrane}

HTPB and TDI were reacted in THF at $30^{\circ} \mathrm{C}$ in presence of $0.05 \mathrm{wt} \%$ DBTDL as catalyst maintaining $\mathrm{NCO}: \mathrm{OH}$ mole ratio of $2: 1$. After $45 \mathrm{~min}$ of reaction, $100 \mathrm{~mol} \%$ diiminodiamine (A) (with respect to $M_{\mathrm{n}}$ of HTPB) dissolved in THF was added slowly to the reaction mixture with constant stirring. The reaction was continued for further $15 \mathrm{~min}$. The excess solvent and entrapped bubbles were removed from the viscous solution by evacuation. The polyiminourethaneurea film was cast on a clean Teflon $^{\circledR}$ plate. The cast film of thickness $0.15 \mathrm{~mm}$ was left overnight at room temperature for moisture curing followed by thermal curing at $80^{\circ} \mathrm{C}$ for $3 \mathrm{~h}$.

\subsection{Degree of swelling}

The degree of swelling of the membrane was measured by immersing in aqueous phenol solution for $48 \mathrm{~h}$

$\%$ Degree of swelling $=\frac{W_{\mathrm{s}}-W_{\mathrm{d}}}{W_{\mathrm{d}}} \times 100$,

where, $W_{\mathrm{s}}$ denotes the weight of the membrane in swelled condition and $W_{\mathrm{d}}$ the weight of the same before immersion.

\subsection{Pervaporation measurement}

Pervaporation of phenol-water mixture was carried out in a pervaporation cell. It is assembled from two cylindrical half-cells made of stainless steel fastened together by nuts and bolts. The membrane was supported on a sintered stainless steel plate placed at the joint of two cells. The feed liquid was circulated using a microtube pump. The feed temperature was maintained by circulating hot water through the cell jacket. For all measurements the downstream pressure was maintained at $5 \mathrm{~mm}$ by applying vacuum. The permeate vapour was collected in a glass condenser suspended inside a cryogenic trap kept at $-15^{\circ} \mathrm{C}$.

\subsection{Analysis of permeate}

The permeate material collected in glass condenser was analysed for phenol content by volumetric redox titration. Standard $\mathrm{BrO}_{3}^{-} / \mathrm{Br}^{-}$solution was added to acidified diluted permeate and the excess bromine was estimated by iodometric back titration. The flux $(F)$ of permeation was calculated from the following expression

$$
F=\frac{Q}{A \times t}\left(\mathrm{~g} / \mathrm{m}^{2} \mathrm{~h}\right)
$$

where, $Q$ is the weight of permeate (either phenol or water or whole permeate) obtained at time $t$ and $A$ the effective membrane area.

The separation factor for phenol $(\alpha)$ is expressed as

$$
\alpha=\frac{[\text { phenol }]_{\text {perm }}}{[\text { phenol }]_{\text {feed }}} \times \frac{\left[\mathrm{H}_{2} \mathrm{O}\right]_{\text {feed }}}{\left[\mathrm{H}_{2} \mathrm{O}\right]_{\text {perm }}} .
$$




\section{Results and discussion}

Pervaporation of phenol-water mixture was carried out with the variation of phenol concentration in feed from $3-7 \%$ while the temperature was varied from $50-70^{\circ} \mathrm{C}$. It was observed that both the total flux and phenol flux increase with the phenol concentration in feed and temperature (figures 1-3). A maximum total flux $\left(33.8 \mathrm{~g} / \mathrm{m}^{2} \mathrm{~h}\right)$ was obtained at $70^{\circ} \mathrm{C}$ with $7 \%$ phenol in feed. This indicates an increase in phenol diffusion within the membrane with the increase of temperature and phenol concentration in feed. This happened as a result of swelling of polyiminourethaneurea membrane with the increase in phenol concentration and temperature (figure 4).

Separation factor $(\alpha)$ varies with phenol concentration differently at different temperatures (figure 5). When

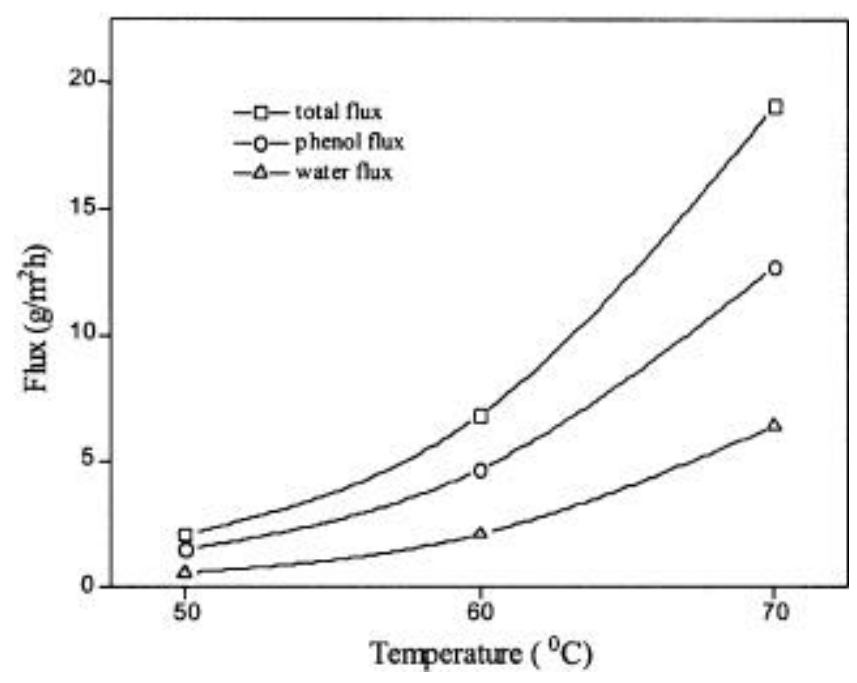

Figure 1. Variation of flux with temperature for $3 \%$ phenol solution in feed.

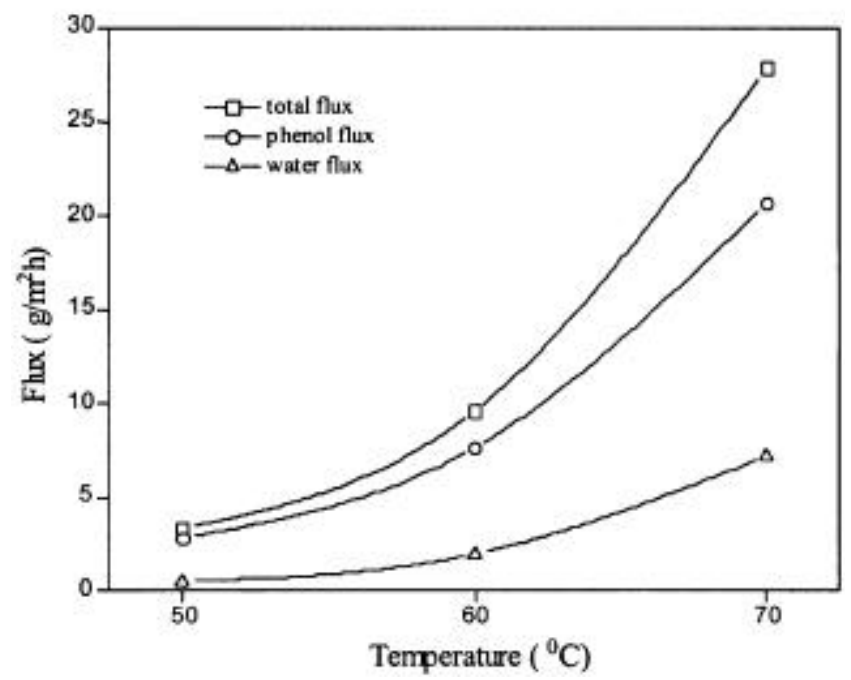

Figure 2. Variation of flux with temperature for 5\% phenol solution in feed. pervaporation was carried out at low temperature $\left(50^{\circ} \mathrm{C}\right)$, the value of separation factor decreases with increasing phenol concentration. The phenol concentration in permeates decreases with increasing temperature at a fixed feed concentration (figure 6). The decrease in phenol selectivity (\% phenol in permeate) at higher temperature is probably due to the rapid rise of water flux with temperature. But the minimum concentration of phenol obtained in permeate was still higher over the earlier reports (Hoshi et al 2000) regarding the separation of phenol at same feed concentration by permselective polyurethane membranes.

Activation energies for phenol permeation $\left(E_{\mathrm{P}}\right)$ at different feed concentrations were obtained from the slope of plot of $\ln F$ against reciprocal of temperature (1/T) (figure 7$)$. The $E_{\mathrm{P}}$ was found to decrease from

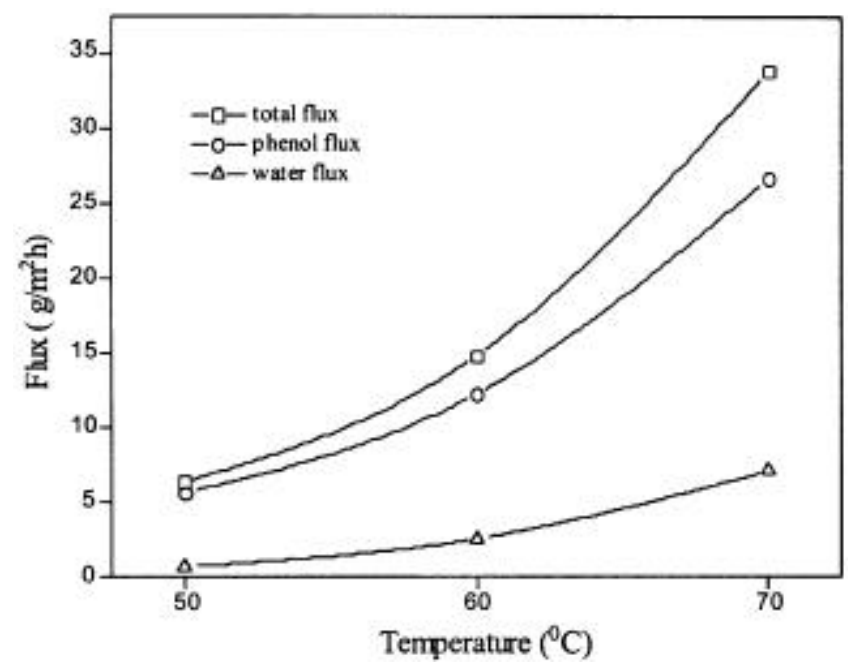

Figure 3. Variation of flux with temperature for $7 \%$ phenol solution in feed.

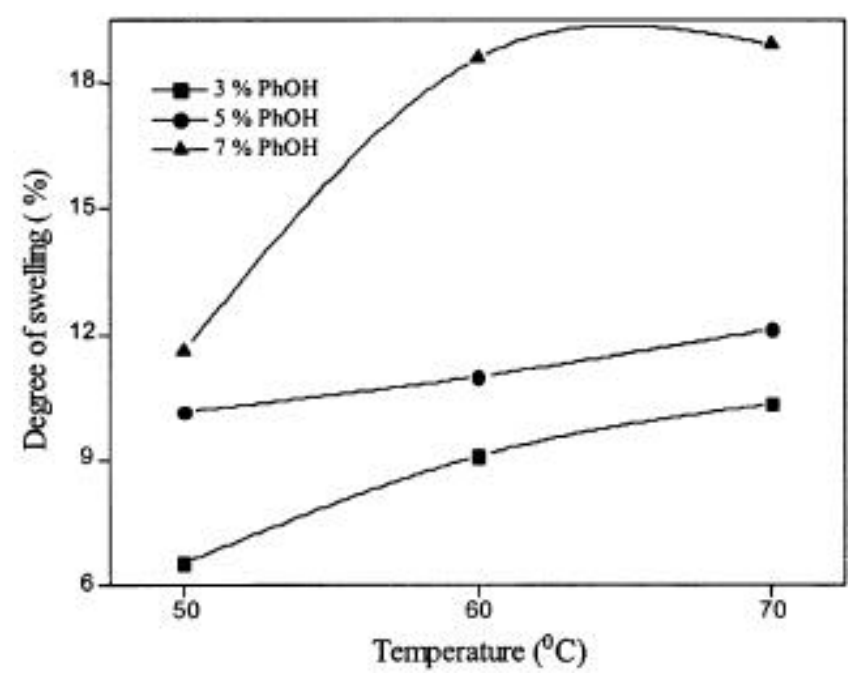

Figure 4. Variation of degree of swelling with temperature. 


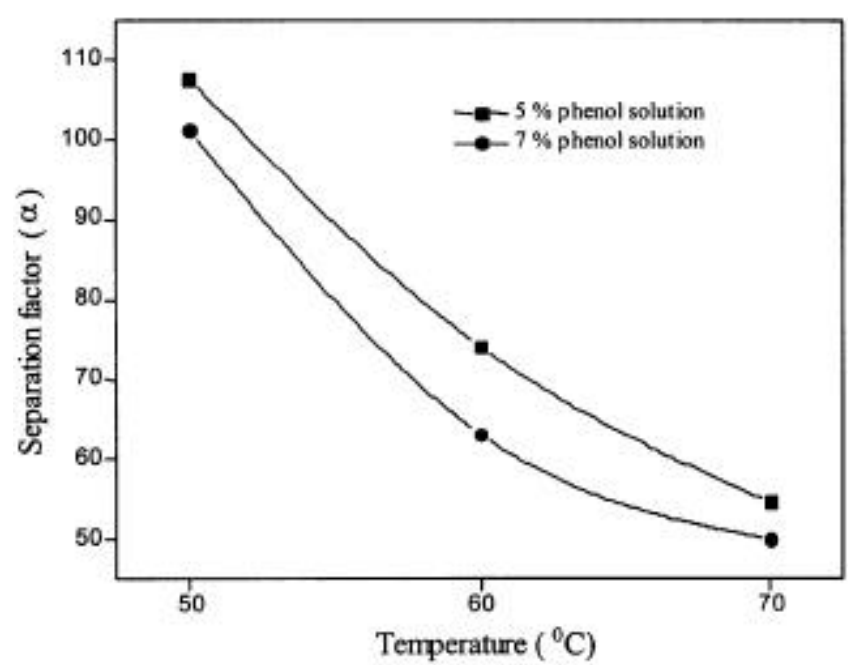

Figure 5. Variation of separation factor of phenol with temperature and phenol concentration in feed.

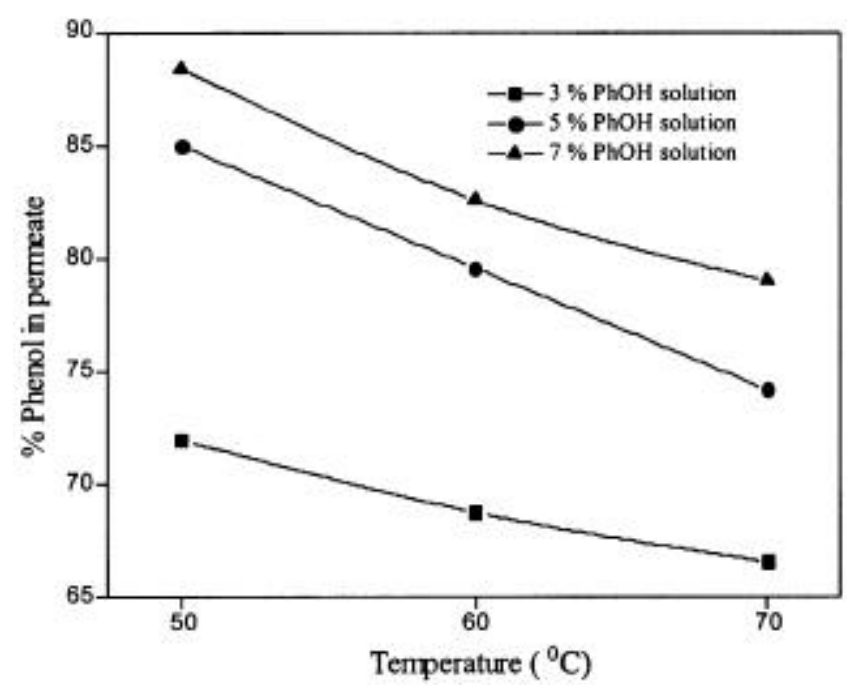

Figure 6. Variation of phenol concentration in permeate for different concentrations of phenol in feed.

$23.6 \mathrm{k} \mathrm{cal} / \mathrm{mol}$ to $18.0 \mathrm{k} \mathrm{cal} / \mathrm{mol}$ with increase in phenol feed concentration from $3-7 \%$. This decrease in activation energy with feed phenol concentration clearly indicates faster permeation leading to higher flux at higher concentrations as observed.

\section{Conclusions}

The separation of phenol from phenol-water mixture was carried out through the polyiminourethaneurea membrane, which showed high phenol selectivity. The phenol selectivity decreases with increase in pervaporation temperature though the phenol flux increases with increase in temperature. The activation energy of permeation is found to decrease at higher phenol concentration in the feed.

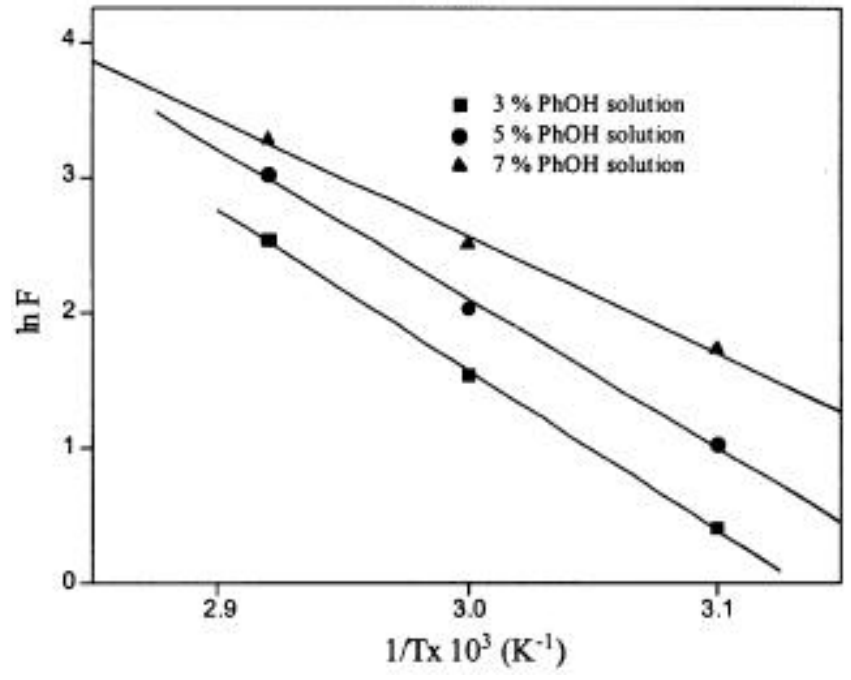

Figure 7. Arrhenius plots for activation energy of permeation for different feed concentrations of phenol.

\section{Acknowledgement}

The authors duly acknowledge the financial assistance provided by the Council of Scientific and Industrial Research, New Delhi, to carry out this investigation.

\section{References}

Bercie G, Pinter A and Levee J 1996 Ind. Eng. Chem. Res. 35 4619

Boddeker K W, Bengston G and Bode E 1990 J. Membr. Sci. 14353

Chen S H, Yu K C, Houng S L and Lai J Y 2000 J. Membr. Sci. 17399

Cook E H, McDonell R P and McNulty J T 1975 Ind. Eng. Chem. Res. Dev. 14113

Ge Y and Jin H 1996 Fuel 751681

Hoshi M, Kogure K, Saitoh T and Nakagawa T 1997 J. Appl. Polym. Sci. 65469

Hoshi M, Ieshige M, Saitoh T and Nakagawa T $2000 \mathrm{~J}$. Appl. Polym. Sci. 76654

Huang S L, Chao M S and Lai J Y 1998 Eur. Polym. J. 34449

Krishnakumar V K and Sharma M M 1984 Ind. Eng. Chem. Process. Des. Dev. 23410

Lee K R, Teng M Y, Hsu T N and Lai J Y 1999 J. Membr. Sci. 162173

Mancy K H and Weber W J 1971 Analysis of industrial waste water (New York: Wiley-Interscience)

Ray S K, Sawanth S B, Joshi J B and Pangarkar V G 1997 Sep. Sci. Technol. 322669

Uramoto H, Kawabata N and Termoto M 1991 J. Membr. Sci. 62219

Wu P, Field R W, England R and Brisdon B J $2001 \mathrm{~J}$. Membr. Sci. 190147

Yang J M and Lin H T 2001 J. Membr. Sci. 187159

Zhao C T and de Pinho M N 1999 Polymer 406089 